\title{
Scoring of decomposition: a proposed amendment to the method when using a pig model for human studies *
}

Original communication

Keough Natalie, $\mathrm{PhD}^{1}$, Myburgh Jolandie, $\mathrm{PhD}^{1}$, Steyn Maryna, $\mathrm{MBChB}, \mathrm{PhD}^{2}$

${ }^{1}$ Forensic Anthropology Research Centre, Department of Anatomy, University of Pretoria, Private Bag x323, Arcadia, 0007

${ }^{2}$ Human Variation and Identification Research Unit, School of Anatomical Sciences, Faculty of Health Sciences, 7 York Road, Parktown 2193, University of the Witwatersrand

Corresponding author: $\underline{\mathrm{N} \text { Keough }}$

Department of Anatomy, University of Pretoria, Private Bag x323, Arcadia, 0007

Contact number: +27123192235 or +27823938519

Email: natalie.keough@up.ac.za

\footnotetext{
* This research was funded by the National Research Foundation (NRF) of South Africa (through M Steyn). Any opinions, findings and conclusions expressed in the article are those of the authors and therefore the NRF does not accept any liability in regard thereto
} 


\begin{abstract}
Decomposition studies often use pigs as proxies for human cadavers. However, differences in decomposition sequences/rates relative to humans have not been scientifically examined. Descriptions of five main decomposition stages (humans) were developed and refined by Galloway and later by Megyesi. However, whether these changes/processes are alike in pigs is unclear. Any differences can have significant effects when pig models are used for human PMI estimation.
\end{abstract}

This study compared human decomposition models to the changes observed in pigs. Twenty pigs $(50-90 \mathrm{~kg})$ were decomposed over five months and decompositional features recorded. Total body scores (TBS) were calculated.

Significant differences were observed during early decomposition between pigs and humans. An amended scoring system to be used in future studies was developed.

Standards for PMI estimation derived from porcine models may not directly apply to humans, and may need adjustment. Porcine models, however, remain valuable to study variables influencing decomposition.

Keywords: forensic science; forensic anthropology; taphonomy; postmortem interval; human decomposition; Total body score; Accumulated degree days; 


\section{Introduction}

The estimation of postmortem interval (PMI) is important in medico-legal investigations as PMI can substantiate witness testimony in a court of law, and can be used to exclude/include possible suspects from a crime scene. Furthermore, if the PMI of decomposed remains can be estimated, the number of potential deceased persons is greatly reduced, thereby improving the possibility for a positive identification $(1,2)$. Decomposition of the human body involves a variety of complex processes (autolysis, putrefaction, decay) which ultimately result in the reduction of a fleshed body to skeletal elements.

Descriptions of the stages of decomposition have been developed by Galloway (1) and refined by Megyesi et al. (2), and are based on decompositional changes observed in humans. However, most experimental studies on decomposition make use of pig carcasses rather than human cadavers. Pig models have widely been accepted as a means to evaluate the process of decomposition (3-10). Pigs are accepted as ideal due to their similarities with humans with regard to the internal anatomy, intestinal flora, fat-to-muscle ratio, hair follicles, sweat glands and skin thickness (10-15). Furthermore, pig carcasses are more readily available and require less vigorous ethical considerations, therefore greatly increasing the sample sizes. Decompositional studies using human cadavers are often retrospective in nature and longitudinal studies are limited. By using pig models, longitudinal studies and taphonomic influences on decomposition can be performed (16-18). Even though pig carcasses are increasingly used for research, it should be kept in mind that differences in the general anatomy, intestinal bacteria, living conditions and zoonotic diseases can lead to variations in the decay process between pigs and humans. No published information evaluating differences in the sequence and rate of decomposition of pigs to the sequence and rate of humans exists.

The use of qualitative decomposition methods to determine PMI uses the assumption that decomposition can only be visually described. However, as shown by Megyesi et al. (2), 
quantitative methods can also be used to statistically assess and score the process of decomposition. The process of decomposition was found to be more dependent on the Accumulated Degree Days (ADD) - i.e., the temperature or cumulative number of degrees a body has been exposed to than the actual elapsed time period. The use of quantitative scoring for decomposition based on visual aspects of the process does add a certain level of consistency. It allows the researcher to draw more meaningful results from a large amount of qualitative data and in so doing provide a summary of results presented in numerical terms with a specified degree of confidence (19). Although Megyesi et al. (2) utilised retrospective data to develop qualitative results, this system allows future decomposition studies the possibility for reproducibility, consistency, comparability and validity. In their study, Megyesi et al. (2) assessed 68 human bodies from various regions and developed a scoring system based on the degree of decomposition (adapted from Galloway et al., 1989). These authors observed the head and neck, trunk and limbs separately, assigning a possible score of 1 to 13,1 to 11 and 1 to 10 respectively for the three regions of the body based on the changes observed. These three scores were then added to give an overall Total Body Score (TBS) for a particular body. The TBS scores were then used in further calculations, and have also since been used in various other studies in several regions of the world (16,18,20-31). Most of these studies were, however, conducted on pig or rabbit remains and no systematic review, analysis or validations of the Megyesi et al. TBS scoring system on pig remains has been done since their original study.

Moffatt et al. (32) observed shortcomings in the scoring and statistical analysis of the study done by Megyesi et al. (2). The study by Moffatt and colleagues provides not only an improved equation for the estimation of ADD, but also suggests making use of a scoring scale which starts at zero instead of three, resulting in improved overall results in predicting PMI. Since the current study did not focus on the improvement of PMI estimates, but rather 
highlighted the differences observed of how decomposition patterns progress between human and pig carcasses, the original scoring system of Megyesi et al. (2) was used.

In a series of pig decomposition studies conducted in South Africa (16-18), it was noted that there were some consistent differences between the published progression $(1,2)$ of decomposition in humans and its scoring, and that observed on the pig remains. The aim of this paper was therefore to describe the differences observed between the published, human decomposition model (2) and the actual, observed decompositional changes in pigs from the fresh stage to complete skeletonization. Using the principles of scoring TBS, a revised method of scoring in the early stages of decomposition, when using a pig model, is proposed. This will ensure that future studies using pigs as a reference sample are comparable, with consistent scoring methods.

\section{Materials and Methods}

A sample of 20 pig carcasses, ranging between $50 \mathrm{~kg}$ and $90 \mathrm{~kg}$, were placed during the spring/summer period of August to December in an open field on the Forensic Anthropology Body Farm (FABF), located on the University of Pretoria's Miertjie le Roux Experimental

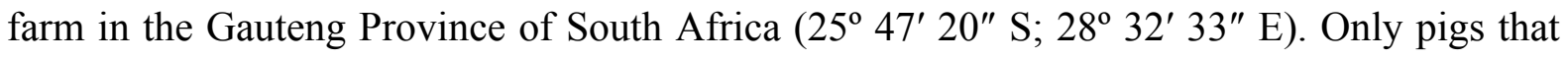
died of natural causes, with no external wounds, were used and were placed at least $5 \mathrm{~m}$ from each other, within 12 hours after death. Death was speculated to have been a result of Listeria (Listeria monosytogenes), E. coli (Escherichia coli) or a Clostridium (Clostridium perfringens) infection. Ethics clearance was obtained (134/2008) before commencement of the study.

The state of decomposition was assessed and scored, using the TBS method developed by Megyesi et al. (2). The scoring guidelines were applied to the three body regions; head and neck, trunk and limbs, since the manner and rate of decomposition has been shown to differ 
between these anatomical regions. The three regions of the body were scored independently and the allotted point value from each region was then added to reach the Total Body Score (TBS), which represents the overall stage of decomposition for each pig. The scores and sequence of decomposition characteristics were observed and compared to the standard description (developed on humans) in order to determine whether differences exist between patterns of pig decomposition and human decomposition. Data collection occurred three times a week until the end stages of advanced decomposition when data collection only took place once a week for each pig (total of 5 months of data collection). Photographs were also taken to accompany every recorded description.

\section{Results}

The most noticeable differences in the decomposition pattern between pigs and humans were observed during the early stages of decomposition and are outlined below. No differences were seen in the morphology and sequence of decomposition during advanced decomposition and skeletonization. Throughout the study, "normal" insect activity and decomposition rates were observed.

\section{Head and Neck}

The changes observed in the decomposition of the head and neck of pig carcasses differed from those described for humans (Table 1). Lividity was prominent in the fresh stage of decomposition (<12-24 hrs.) in all pig carcasses (Fig. 1), while it is not included in the scoring method for humans; thus assuming that it was not a major feature noted in the human studies. Skin slippage and hair loss in humans are features associated with early decomposition (Table 1; pt. = 2) while in pigs this change was only seen towards the end stages of early decomposition (just before advanced decomposition begins) together with 
discolouration and/or brown shades around the edges and purging of the decompositional fluids (Table 1; pts. $=4 / 5$ ). No green-grey discolouration of the head or neck region was observed on the pig carcasses; instead this colour change was more red to dark-red (darkening of lividity) with some areas of relatively fresh tissue (Fig. 1). Bloating was observed in the neck together with red to dark-red discolouration (grey-green in humans, pt. = 3; Table 1). This red to dark-red discolouration morphed into browner shades, particularly around the edges (Table 1; pt. $=4$ ) but no drying out of the nose, ears or lips was noted until purging of the decompositional fluids (Table 1; pt. =5). Drying of the nose, ears and lips in human specimens occurs before purging of decompositional fluids.

Trunk

The changes observed in the decomposition of the trunk of pig carcasses differed considerably from those described for humans (Table 2). No pink-white discolouration (Table $2 ; \mathrm{pt} .=2$ ) of the skin of the trunk was noted, instead, the skin appeared glossy, giving it a polished, granite-like effect (Fig. 2). Skin slippage and marbling appeared in conjunction with purging of decompositional fluids (Table 2; pt. $=4$ ) and grey-green/green discolouration of the abdomen (Table 2; pt. = 3) respectively, and not in the beginning of early decomposition as noted on human specimens (Table 2; pt. $=2$ ). Furthermore, an inconsistent purplish-black discolouration was noted on the abdominal area (covering distal intestines) which is not described in human decomposition studies (Fig. 3). Bloating presented together with the earlier colour changes to the skin with marbling (Table 2; pts. $2 \& 3$ ) and not towards the later stages $(\mathrm{pt.}=4)$ as expected in human progression (Fig. 4). During decomposition of the trunk in pigs, the appearance of "maggot-filled blisters" was noted together with increasing amounts of skin slippage and hair loss (Fig. 5). 
Limbs

The most noticeable differences with the progression and scoring of decomposition were observed during decomposition of the limbs (Table 3). Rigor mortis occurred rapidly in all the pig carcasses (within 12-24 hours) with pink/white discolouration of the skin appearing in less than $20 \%$ of the pigs in the early stage (Fig. 6). The majority of the pigs showed no pink/white discolouration of the limbs but rather the skin retained its natural colour with darkening of lividity (Fig. 1). Bloating of the limbs (proximal parts), which is absent in the standard scoring technique for humans, was noted before the grey-green discolouration. Skin slippage, hair loss and a shiny/polished appearance was noted only once the limbs discoloured (grey-green) and not as early as indicated in the standard human scoring technique. The skin of the limbs also dried out starting at the distal end and moving proximally with the proximal ends of the limbs showing more maggot activity.

In order to determine inter-rater reliability, an external individual scored decomposition for the head and neck, trunk, limbs and a Pearson's correlation test was performed. As seen in Table 4, a high level of correlation existed between observers.

\section{Discussion}

The early stages of decomposition are greatly influenced by several external factors such as seasonality (summer, winter), insect activity, scavenging, and humidity (35). Although the general sequence in which decomposition occurs remains relatively consistent in pig carcasses, the chronological order of decompositional changes, compared to humans, varies. This study made use of the standards set and refined by Galloway et al. (1) and later revised and enhanced (TBS) by Megyesi et al. (2) to score the various stages of decomposition. Although these standards were developed using retrospective human decomposition data, the 
authors assumed that these are the general accepted standards for decomposition studies and would be comparable with pigs.

Sequential changes in the process of decomposition should technically not differ; however, due to the chronological differences observed in this study, it is recommended that they should not be directly applied to studies making use of pigs, as sample overestimation, albeit small, of TBS will most likely result (16-18). The discrepancies between the sequences of decompositional changes observed in humans, and the data obtained from the current study were noted on more than one occasion and are presented in Tables 1-3 and the differences in scoring methodologies are visually presented in Tables 5-7. These figures schematically demonstrate the difference in timing of certain processes of decomposition (onset of skin and hair loss, bloating, purging of decompositional fluids) between human data and that which was observed in the pig sample of the current study. These discrepancies arose mainly in the earlier stages of decomposition and as soon as the pigs progressed into the advanced stages, they emulated the sequences set by Galloway and Megyesi.

The main discrepancies noted in scoring the head and neck, the trunk and the limbs were with the timing at which bloating occurred. In the pig sample, the onset of bloating in the neck began even before the skin changed to brownish shades and before purging of decompositional fluids occurred. A previous study conducted by Anderson and VanLaerhoven (36) found that bloating, colour changes and marbling appeared within the fresh/early stages of decomposition $(2-10$ days $)$ in their pig sample $(n=7)$. According to the timing of the bloating of the neck in the current study, a score of no more than 3 should have been given instead of a 5 which would over-score the pig by 2 points (Table 5). Megyesi et al. (2) allocated a score of 4 for the appearance of bloating in the trunk, whereas in this study bloating occurred as soon as 2 days after death, before any grey-purple-green discolouration $($ score $=3$ ) (Table 6). Therefore, during data collection the authors had to 
consider the possibility of over-scoring the pigs if the standard human scoring method was used based on the actual known PMIs. Since most of the decomposition features were found to occur earlier in the pig sample, the authors (if unsure) should rather provide a lower score than the higher score indicated in the human scoring method. For example, if bloating was present in the pigs regardless of region, a lower score of $2 / 3$ should be given instead of the higher scores of $4 / 5$, indicated in the human scoring method for the appearance of bloating (16-18). One of the possible reasons why bloating may occur earlier in pigs than in humans is that pigs are generally considered dirty (unhygienic) animals and may contain more/different intestinal flora with the addition of external bacteria within the pens they are kept, when compared to humans. This possible increased or heightened bacterial internal and external load may accelerate the production of internal gases defining the appearance of bloating.

Aside from the internal aspects, the pens in which pigs are generally kept may allow faster access of Diptera colonisations which may occur within seconds after death allowing egg oviposition prior to placement of carcasses for study purposes; essentially initial decomposition processes may begin prior to the start of a study. This may also accelerate general decomposition but as to date, no literature is available comparing actual decomposition rates between pigs and human specimens within the same environment. Although similar discrepancies observed with timing of colour changes and the presence of skin slippage and hair loss were noted, their influence on the scoring was not as significant as seen with the bloating. If anything, these variations would under-estimate the stage of decomposition if they were the only observable factor.

The assumption remains that due to similarities between human and pig anatomies that these two species should decompose at relatively the same rates and in general, in the same sequence. However, in addition to the chronological order of decomposition features varying slightly, some additional characteristics were noted in the different stages of 
decomposition (not noted in human studies). Oedema of the ears (Fig. 7) and limbs (swelling) was noted in the early stages of decomposition together with the shiny, polished appearance of the skin of the trunk. The factors discussed above have been considered and a modified version for staging and scoring of decomposition for the head and neck (Table 8), the trunk (Table 9) and the limbs (Table 10) using a pig model is presented. It is advised that these should be used in future pig studies, at least in a southern Africa context. Similar studies from other regions of the world are needed to confirm and validate these findings. In the three studies conducted at the FABF (16-18), the scoring method proposed by Megyesi was used as it is an accepted standard, but in future studies where pig carcasses are used these differences need to be taken into account.

This study also brings to light the differences that exist in the decomposition patterns between human and pig carcasses which serve as a cautionary note when using pig studies to derive formulae to estimate PMI in a forensic setting. It is unfortunate that in a number of research institutes the use of human bodies to study decomposition is not possible. Since pigs are more commonly used across the globe for these taphonomic studies, it should be a top priority to compare directly the decomposition process of a pig carcass with a human body in the same environment, concurrently. As noted in this current study, there is a definite difference in the early stages of decomposition, which needs to be addressed in order to optimize the use of pigs in these comparative studies. Under the circumstances, the best application of pig studies would be to develop a better understanding of the process of decomposition and to use pig carcasses as proxies to study the effect of other variables on the decomposition process rather than to produce direct estimates used on human remains in a forensic setting - for example, using small and large bodied pig carcasses to study the effect of body size on the rate and pattern of decomposition (Sutherland et al., 2013). 
The adjustment to the scoring method proposed here will not alter the results of these studies dramatically, but could subtly change some of the results, especially in the early stages. This is something to be investigated in the future in order to translate it back to the reciprocal TBS score in humans especially if the purpose of any future study is to assess early decomposition.

\section{Conclusion}

In conclusion, the results of this study indicate that the early stages of decomposition differ considerably between pigs and humans especially with regard to the onset of bloating. There is no doubt that our field lacks robust studies in which comparisons between pig and human decomposition is made directly. The implications that this may have on the use of these models on pig studies, and in turn, the application of methods derived from these studies to estimate post-mortem interval, should be considered. A modified version for scoring decomposition using a pig model is presented (Tables 8-10) and it is advised that these be used and perhaps verified for future studies. 


\section{Acknowledgements}

The authors would like to thank Roelf Coertze, Melvin Trollope and the Faculty of Natural and Agricultural Sciences (UP) for supplying the pigs and the premises to conduct this study. Thank you to Prof EN L'Abbé for continued support as a scientific advisor and Mrs M Pretorius for assistance with the graphic work. 


\section{References}

(1) Galloway A, Birkby WB, Jones AM, Henry TE, Parks BO. Decay rates of human remains in an arid environment. J. Forensic Sci 1989;34:607-16

(2) Megyesi MS, Nawrocki SP, Haskell NH. Using accumulated degree-days to estimate the postmortem interval from decomposed human remains. Forensic Sci. Int $2005 ; 50: 618-26$

(3) Payne JA, King EW. Arthropod Succession and Decomposition of Buried Pigs. Nature 1968;219:1180-81

(4) Terneny TT. Estimation of time since death in humans using mature pigs. [Masters' Thesis], Montana (MT): Univ. of Montana, 1997

(5) Shalaby OA, DeCarvalho LM, Goff ML. Comparison of Patterns of Decomposition in a Hanging Carcass and a Carcass in Contact with Soil in Xerophytic Habitat on the Island of Oahu, Hawaii. J Forensic Sci 2000;45:1267-73.

(6) Schiel M. Using Accumulate Degree Days for Estimating the Postmortem Interval: A Re-Evaluation of Megyesi's Regression Formulae. [Masters' thesis], Indiana (IN), Univ. of Indianapolis, 2008

(7) Bunch AW. The impact of cold climate on the decomposition process. J For Identification 2009;59:26-44. 
(8) Callahan CA. Vegetation Colonization of Experimental Grave Sites in Central Texas. [Masters' thesis], Texas (TX), Texas State University, 2009

(9) Fitzgerald CM, Oxenham M. Modelling time-since-death in Australian temperate conditions. Australian J Forensic Sci 2009;41:27-41.

(10) Reeves NM. Taphonomic Effects of Vulture Scavenging. J Forensic Sci 2009;54:52328.

(11) Hopewell JW. Biological effects of irradiation on skin and recommended dose limits. Radiation Protection Dosimetry 1991;39:11-24

(12) Goff ML. Estimation of the Postmortem Interval using Arthropod Development and Successional Patterns. Forensic Sci Rev 1993;81:81-94.

(13) Hall EJ. Radiobiology for the radiologist. 3rd ed. Philadelphia: JB Lippincott Company, 1988

(14) Byrd JH, Castner JL. Forensic entomology: the utility of arthropods in legal investigations. Boca Raton: CRC Press, 2001

(15) Pakosh CM, Rogers TL. Soft Tissue Decomposition of Submerged, Dismembered Pig Limbs Enclosed in Plastic Bags. J Forensic Sci 2009;54:1223-28. 
(16) Myburgh J, L'Abbé EN, Steyn M, Becker PJ. Estimating the postmortem interval (PMI) using accumulated degree-days (ADD) in a temperate region of South Africa. Forensic Sci Int 2013;229:165-e1.

(17) Keough N, L'Abbe EN, Steyn M, Pretorius S. Assessment of skeletal changes after post-mortem exposure to fire as an indicator of decomposition stage. Forensic Sci Int $2015 ; 246: 17-24$

(18) Sutherland A, Myburgh J, Steyn M, Becker PJ. The effect of body size on the rate of decomposition in a temperate region of South Africa. Forensci Sci Int 2013;231:25762

(19) Abeyasekera S. "Quantitative analysis approaches to qualitative data: why, when and how", Statistical Services Centre, University of Reading, 2000

(20) Bachmann J, Simmons T. The influence of preburial insect access on the decomposition rate. J Forensic Sci 2010;55:893-900

(21) Cross P, Simmons T. The influence of penetrative trauma on the rate of decomposition. J Forensic Sci 2010;55:295-301

(22) Simmons T, Cross P, Adlam RE, Moffatt C. The influence of insect on decomposition rate in buried and surface remains. J Forensic Sci 2010;55:889-92 
(23) C.L. Parks. A study of the human decomposition sequence in central Texas. J Forensic Sci 56(2011) 19-22

(24) Spika A, Johnson R, Bushing J, Higley LG, Carter DO. Carcass mass can influence rate of decomposition and release of ninhydrin-reactive nitrogen into gravesoil. Forensic Sci Int 2011;209:80-85

(25) Suckling JK. A longitudinal study on the outdoor human decomposition sequence in central Texas. [Masters' Dissertation], Texas (TX), Texas State University-San Marcos, 2011

(26) Meyers J, Anderson B, Carter DO. Seasonal variation of carcass decomposition and gravesoil chemistry in a cold (Dfa) climate. J Forensic Sci 2013;58:1175-82

(27) Smith AC. The effect of sharp-force thoracic trauma on the rate and pattern of decomposition. J Forensic Sci 2013;59:319-26

(28) Troutman L, Moffatt C, Simmons T. A preliminary examination of differential decomposition patterns in mass graves. J Forensic Sci 2014;59:621-26

(29) Card A, Cross P, Moffatt C, Simmons T. The effect of clothing on the rate of decomposition and Diptera colonization on Sus scrofa carcasses. J Forensic Sci 2015;60:979-82 
(30) Marhoff SJ, Fahey P, Forbes SL, Green H. Estimating post-mortem interval using accumulated degree-days and a degree of decomposition index in Australia: a validation study. A J Forensic Sci (online) DOI:10.1080/00450618.2015.1021378, 2015

(31) Suckling JK, Spradley MK, Godde K. A longitudinal study on human outdoor decomposition in Central Texas. J Forensic Sci (online) DOI: 10.1111/15564029.12892, 2015

(32) Moffatt C, Simmons T, Lynch-Aird J. An improved equation for TBS and ADD: establishing a reliable postmortem interval framework for casework and experimental studies. J Forensic Sci 2016;61 Suppl 1:S201-S07

(33) Benhin JKA. Climate change and South African Agriculture: Impacts and adaptation options. CEEPA Discussion paper No. 21 Center for Environmental Economics and Policy in Africa, University of Pretoria, 2006

(34) Teie WC. Fire manager's handbook on veld and forest fires: Strategy, tactics and safety. South African Institute of Forestry, 2005

(35) Mann RW, Bass WM, Meadows L. Time since death and decomposition of the human body: variables and observations in case and experimental field studies. J Forensic Sci. 1990;35:103-11 
(36) Anderson GS, VanLaerhoven SL. Initial studies on insect succession on carrion in Southwestern British Columbia. J Forensic Sci 1996;41:617-25 
Additional Information and Reprints Available from Author

Corresponding author: Natalie Keough, Dr

Department of Anatomy, University of Pretoria, Private Bag x323, Arcadia, 0007

Contact number: +27123192235 or +27823938519

Email: natalie.keough@up.ac.za 
Table 1: Results for scoring the decompositional stage for the head and neck. The differences observed in the porcine/pig carcasses are showed in bold.

\begin{tabular}{|c|c|c|c|}
\hline Decomp stage & Megyesi/Galloway Characteristics & Pts & Current study \\
\hline Fresh & No discolouration & 1 & $\begin{array}{l}\text { No discolouration - slight lividity } \\
\text { (pink/red) }\end{array}$ \\
\hline \multirow[t]{4}{*}{ Early } & $\begin{array}{l}\text { Pink, white appearance, skin slippage } \\
\& \text { some hair loss }\end{array}$ & 2 & $\begin{array}{l}\text { Pink, white appearance. No skin } \\
\text { slippage or hair loss. Insect activity } \\
\text { (blue-bottle and brown flies). } \\
\text { Lividity more pronounced. }\end{array}$ \\
\hline & $\begin{array}{l}\text { Grey - Green discolouration, some } \\
\text { flesh still relatively fresh }\end{array}$ & 3 & $\begin{array}{l}\text { No grey-green discolouration. } \\
\text { Discolouration (dark-red), oedema } \\
\text { of ears (fluid filled), some flesh still } \\
\text { relatively fresh. Maggot } \\
\text { colonization in mouth. Some } \\
\text { bloating of neck region, some skin } \\
\text { slippage. }\end{array}$ \\
\hline & $\begin{array}{l}\text { Discolouration and/or brown shades } \\
\text { particularly at edges, drying of nose, } \\
\text { ears \& lips }\end{array}$ & 4 & $\begin{array}{l}\text { Discolouration and/or brown shades } \\
\text { particularly at edges. Bloating of } \\
\text { neck, some hair loss. No drying of } \\
\text { ears, lips and nose. Maggot } \\
\text { colonization in mouth and eyes, } \\
\text { some purging of decompositional } \\
\text { fluids }\end{array}$ \\
\hline & $\begin{array}{l}\text { Purging of decomposition fluids out of } \\
\text { eyes, ears, nose, and mouth. Some } \\
\text { bloating of neck \& face }\end{array}$ & 5 & $\begin{array}{l}\text { Purging of decomposition fluids out } \\
\text { of eyes, ears, nose, mouth, brown } \\
\text { discolouration. Hair loss and skin } \\
\text { slippage. Extensive maggot } \\
\text { colonization in eyes, mouth. Drying } \\
\text { out of lips, nose and ears }\end{array}$ \\
\hline
\end{tabular}




\begin{tabular}{|l|l|l|l|}
\hline & Brown - Black discolouration of flesh & 6 & $\begin{array}{l}\text { Black discolouration of flesh, with } \\
\text { maggot colonization }\end{array}$ \\
\hline
\end{tabular}


Table 2: Results for scoring the decompositional stages of the trunk. The differences observed in the porcine/pig carcasses are showed in bold.:

\begin{tabular}{|c|c|c|c|}
\hline Decomp stage & Megyesi/Galloway Characteristics & Pts & Current study \\
\hline Fresh & No discolouration & 1 & $\begin{array}{l}\text { No discolouration. Some lividity } \\
\text { (red/pink) }\end{array}$ \\
\hline \multirow[t]{4}{*}{ Early } & $\begin{array}{l}\text { Pink, white appearance, skin slippage } \\
\text { and marbling present }\end{array}$ & 2 & $\begin{array}{l}\text { No pink, white appearance, skin } \\
\text { displays a shiny/polished } \\
\text { appearance (glossy marble) with } \\
\text { bloating present. No skin slippage } \\
\text { or marbling. Inconsistent purplish- } \\
\text { black discolouration over } \\
\text { abdominal area specifically over } \\
\text { intestines }\end{array}$ \\
\hline & $\begin{array}{l}\text { Grey-green discolouration, some flesh } \\
\text { still relatively fresh }\end{array}$ & 3 & $\begin{array}{l}\text { Grey-Purple or green } \\
\text { discolouration, marbling of } \\
\text { abdomen with maximum bloating, } \\
\text { some flesh still relatively fresh, some } \\
\text { hair loss }\end{array}$ \\
\hline & $\begin{array}{l}\text { Bloating with green discolouration \& } \\
\text { purging of decompositional fluids }\end{array}$ & 4 & $\begin{array}{l}\text { Bloated, purple-black discolouration, } \\
\text { purging of decompositional fluids, } \\
\text { skin slippage with maggot filled } \\
\text { blisters }\end{array}$ \\
\hline & $\begin{array}{l}\text { Post bloating following release of } \\
\text { abdominal gases with discolouration } \\
\text { changing from green to black }\end{array}$ & 5 & $\begin{array}{l}\text { Post bloating, sagging of trunk, } \\
\text { black discolouration, skin slippage } \\
\text { and dried blisters }\end{array}$ \\
\hline
\end{tabular}


Table 3. Results for scoring the decompositional stages for the limbs. The differences observed in the porcine/pig carcasses are showed in bold.

\begin{tabular}{|c|c|c|c|}
\hline Decomp stage & Megyesi/Galloway Characteristics & Pts & Current study \\
\hline Fresh & No discolouration & 1 & $\begin{array}{l}\text { No discolouration. Some lividity } \\
\text { and rigor mortis present }\end{array}$ \\
\hline \multirow[t]{4}{*}{ Early } & $\begin{array}{l}\text { Pink, white appearance, skin slippage } \\
\text { of hands \& feet }\end{array}$ & 2 & $\begin{array}{l}\text { Slight pink-white appearance }(< \\
20 \% \text { of pigs), no skin slippage of } \\
\text { limbs. Some bloating/swelling of } \\
\text { proximal part of limbs. }\end{array}$ \\
\hline & $\begin{array}{l}\text { Grey-Green discolouration; marbling, } \\
\text { some flesh still relatively fresh }\end{array}$ & 3 & $\begin{array}{l}\text { Grey-Green discolouration, marbling, } \\
\text { some flesh still relatively fresh, skin } \\
\text { having a shiny appearance. Skin } \\
\text { slippage and hair loss on limbs }\end{array}$ \\
\hline & $\begin{array}{l}\text { Discolouration and/or brown shades } \\
\text { particularly at edges, drying of fingers } \\
\text { \& toes \& other projecting extremities }\end{array}$ & 4 & $\begin{array}{l}\text { Discolouration and/or brown shades } \\
\text { proximal; and drying out of skin } \\
\text { (distal to proximal). }\end{array}$ \\
\hline & $\begin{array}{l}\text { Brown - Black discolouration, skin } \\
\text { having leathery appearance }\end{array}$ & 5 & $\begin{array}{l}\text { Brown - Black discolouration, skin } \\
\text { having a leathery appearance or } \\
\text { sloughing off }\end{array}$ \\
\hline
\end{tabular}


Table 4. Correlation coefficients for the inter-observer results.

\begin{tabular}{|l|c|}
\hline Description score & Correlation coefficient \\
\hline Head and Neck & 0.981 \\
Trunk & 0.985 \\
Limbs & 0.990 \\
Total Body Score & 0.992 \\
\hline
\end{tabular}


Table 5. Discrepancies in the onset timing and therefore point allocation for skin slippage* , hair $\operatorname{loss}^{\dagger}$, and bloating ${ }^{\S}$, as well as the purging of decompositional fluids ${ }^{\ddagger}$ in the head and neck region.

\begin{tabular}{|l|c|c|c|c|c|c|c|c|}
\hline & FRESH & \multicolumn{6}{|c|}{ EARLY DECOMPOSITION } \\
\hline Megyesi et al 2005 & & $*$ & $\dagger$ & & & $\dagger$ & $\S$ & \\
\hline Scoring for head and neck & $1 \mathrm{pt}$ & $2 \mathrm{pts}$ & $3 \mathrm{pts}$ & $4 \mathrm{pts}$ & $5 \mathrm{pts}$ & $6 \mathrm{pts}$ \\
\hline Current study (pigs) & & & $*$ & $\S$ & $\dagger$ & $\dagger$ & & \\
\hline
\end{tabular}

\footnotetext{
* Denotes the onset of skin slippage

${ }^{\dagger}$ Denotes the onset of hair loss

$\S$ Denotes the onset of bloating

* Purging of decompositional fluids
} 
Table 6. Discrepancies in the onset timing and therefore point allocation for skin slippage $^{*} /$ hair loss ${ }^{\dagger}$, marbling ${ }^{((}$and bloating ${ }^{\S}$ in the trunk region.

\begin{tabular}{|c|c|c|c|c|c|c|}
\hline & FRESH & \multicolumn{5}{|c|}{ EARLY DECOMPOSITION } \\
\hline Megyesi et al 2005 & & $* / \dagger$ & $(($ & & $\S$ & \\
\hline Scoring for trunk & $1 \mathrm{pt}$ & & & $3 \mathrm{pts}$ & $4 \mathrm{pts}$ & $5 \mathrm{pts}$ \\
\hline Current study (pigs) & & & & $(($ & $* / \uparrow$ & \\
\hline
\end{tabular}

\footnotetext{
*Denotes the onset of skin slippage

${ }^{\dagger}$ Denotes the onset of hair loss

(" Denotes the onset of marbling

$\S$ Denotes the onset of bloating
} 
Table 7. Discrepancies in the onset timing and therefore point allocation for skin slippage* Onset of bloating ${ }^{\S}$ as well as hair loss ${ }^{\dagger}$ in the limb region is indicated as a new feature to be scored (these two features are not indicated in Megyesi's method for limbs)

\begin{tabular}{|c|c|c|c|c|c|c|}
\hline & FRESH & \multicolumn{5}{|c|}{ EARLY DECOMPOSITION } \\
\hline Megyesi et al 2005 & & $*$ & & & \\
\hline Scoring for limbs & $1 \mathrm{pt}$ & $2 \mathrm{pts}$ & \multicolumn{2}{|c|}{$3 \mathrm{pts}$} & $4 \mathrm{pts}$ & $5 \mathrm{pts}$ \\
\hline Current study (pigs) & & $\S$ & $*$ & $\dagger$ & & \\
\hline
\end{tabular}

\footnotetext{
${ }^{*}$ Denotes the onset of skin slippage

$\S$ Denote the onset of bloating (not a feature scored in the Megyesi method for limbs)

${ }^{\dagger}$ Denotes the onset of hair loss (not a feature scored in the Megyesi method for limbs)
} 
Table 8. Modified categories and stages of decomposition for the head and neck (pig)

\begin{tabular}{ll}
\hline A & Fresh \\
\hline (1pt) & 1. Fresh, no discolouration - slight lividity (pink/red) \\
\hline B & Early decomposition \\
\hline (2pts) & 1. Insect activity; pronounced lividity (dark pink/red) \\
(3pts) & 2. Dark red discolouration with some flesh still relatively fresh; odema of ears; \\
& maggot colonisation (mouth); initial bloating of neck and skin slippage \\
(4pts) & $\begin{array}{l}\text { 3. Discolouration and/or brownish shades particularly at edges, drying of nose, ears } \\
\text { and lips; prominent bloating of neck; maggot colonisation (mouth \& eyes); purging of }\end{array}$ \\
& decompositional fluids (mouth) \\
(5pts) & 4. Purging of decompositional fluids (mouth, eyes, nose); brown discolouration; hair \\
& loss and skin slippage; drying of lips, nose and ears \\
(6pts) & 5. Black discolouration of flesh; extensive maggot colonisation \\
& and migration
\end{tabular}

$\mathbf{C}$

Advanced decomposition

(7pts) 1. Caving in of the flesh and tissues of eyes and throat

(8pts) 2. Moist decomposition with bone exposure less than one half that of the area being scored

(9pts) 3. Mummification with bone exposure less than one half that of the area being scored

D Skeletonization

(10pts) 1. Bone exposure of more than half of the area being scored with greasy

substances and decomposed tissue

(11pts) 2. Bone exposure of more than half the area being scored with desiccation of mummified tissue

(12pts) 3. Bones largely dry, but retaining some grease

(13pts) 4. Dry bone 
Table 9. Modified categories and stages of decomposition for the trunk (pigs)

\begin{tabular}{ll}
\hline A & \multicolumn{1}{c}{ Fresh } \\
\hline (1pt) & 1. Fresh, no discolouration - slight lividity (pink) \\
\hline B & Early decomposition \\
\hline (2pts) & $\begin{array}{l}\text { 1. Skin appears shiny/glossy with early bloating; may show purple-black } \\
\text { discolouration over abdominal area }\end{array}$ \\
(3pts) & $\begin{array}{l}\text { 2. Grey-purple to green discolouration: some flesh still relatively fresh; marbling } \\
\text { of abdomen with maximum bloat }\end{array}$ \\
(4pts) & $\begin{array}{l}\text { 3. Purple-black discolouration and purging of decompositional fluids; skin } \\
\text { slippage with maggot filled blisters present; hair loss }\end{array}$ \\
(5pts) & 4. Post-bloating following release of the abdominal gases, with extensive skin \\
& slippage and drying out of blisters
\end{tabular}

$\mathbf{C}$

Advanced decomposition

(6pts) 1.Decomposition of tissue producing sagging of flesh; caving in of the abdominal cavity

(7pts) 2. Moist decomposition with bone exposure less than one half that of the area being scored

(8pts) 3. Mummification with bone exposure less than one half that of the area being scored

\section{Skeletonization}

(9pts) 1. Bones with decomposed tissue, sometimes with body fluids and grease still present

(10pts) 2. Bones with desiccated or mummified tissue covering less than one half of the area being scored

(11pts) 3. Bones largely dry, but retaining some grease

(12pts) 4. Dry bone 
Table 10. Modified categories and stages of decomposition for the limbs (pigs)

\begin{tabular}{|c|c|}
\hline $\mathbf{A}$ & Fresh \\
\hline$(1 \mathrm{pt})$ & $\begin{array}{l}\text { 1. Fresh, no discolouration - slight lividity (pink) with } \\
\text { rigor present }\end{array}$ \\
\hline B & Early decomposition \\
\hline (2pts) & 1. Pink-white appearance with bloating of proximal parts of limbs \\
\hline$(3 \mathrm{pts})$ & $\begin{array}{l}\text { 2. Grey to green discolouration: marbling and shiny appearance of skin; some flesh } \\
\text { still relatively fresh; skin slippage and hair loss }\end{array}$ \\
\hline$(4 \mathrm{pts})$ & $\begin{array}{l}\text { 3. Discolouration and/or brownish shades particularly at edges, drying of skin } \\
\text { (starting distal to proximal) }\end{array}$ \\
\hline$(5 \mathrm{pts})$ & 4. Brown to black discolouration, skin having a leathery appearance \\
\hline $\mathbf{C}$ & Advanced decomposition \\
\hline$(6 \mathrm{pts})$ & $\begin{array}{l}\text { 1. Moist decomposition with bone exposure less than one half that of the area being } \\
\text { scored }\end{array}$ \\
\hline$(7 \mathrm{pts})$ & $\begin{array}{l}\text { 2. Mummification with bone exposure less than one half that of the area being } \\
\text { scored }\end{array}$ \\
\hline D & Skeletonization \\
\hline (8pts) & $\begin{array}{l}\text { 1. Bone exposure over one half the area being scored, some decomposed } \\
\text { tissue and body fluids remaining }\end{array}$ \\
\hline (9pts) & 2. Bones largely dry, but retaining some grease \\
\hline (10pts) & 3. Dry bone \\
\hline
\end{tabular}




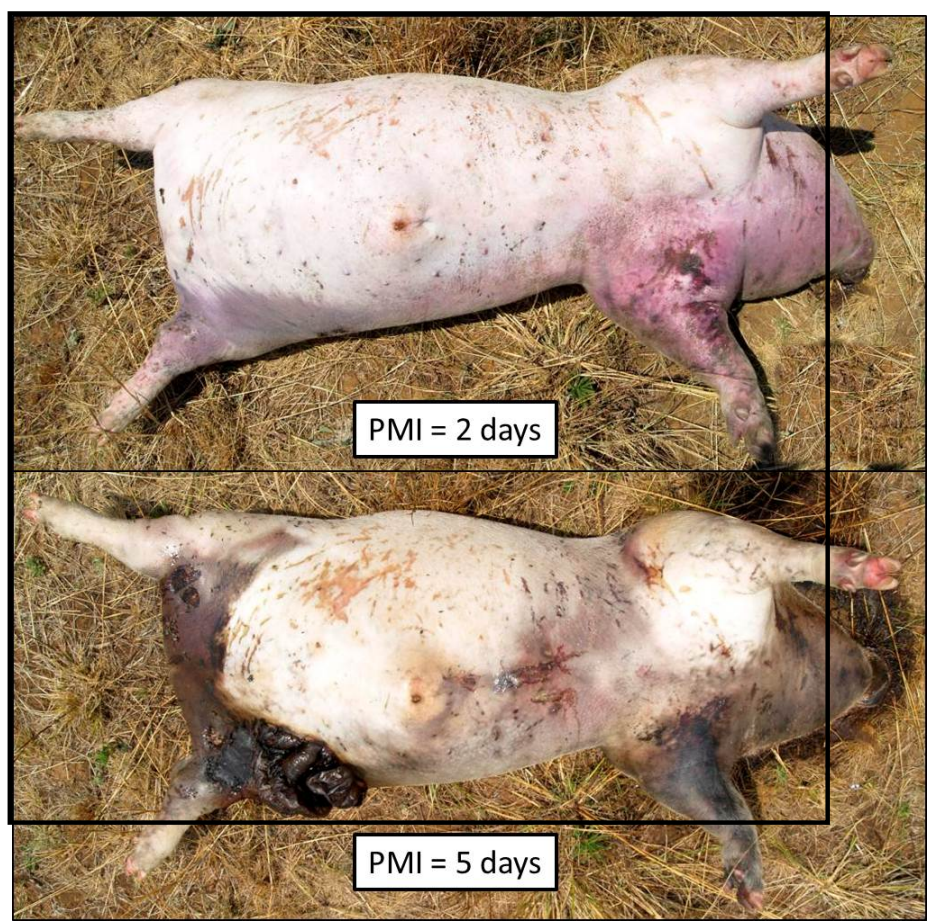

Figure1. Lividity observed in the fresh stage of decomposition $(<12-24 \mathrm{hrs})$ in all pig carcasses with darkening of the lividity (observed on the left head and neck, left front limb, left abdominal region and left hind limb) after 24 hours

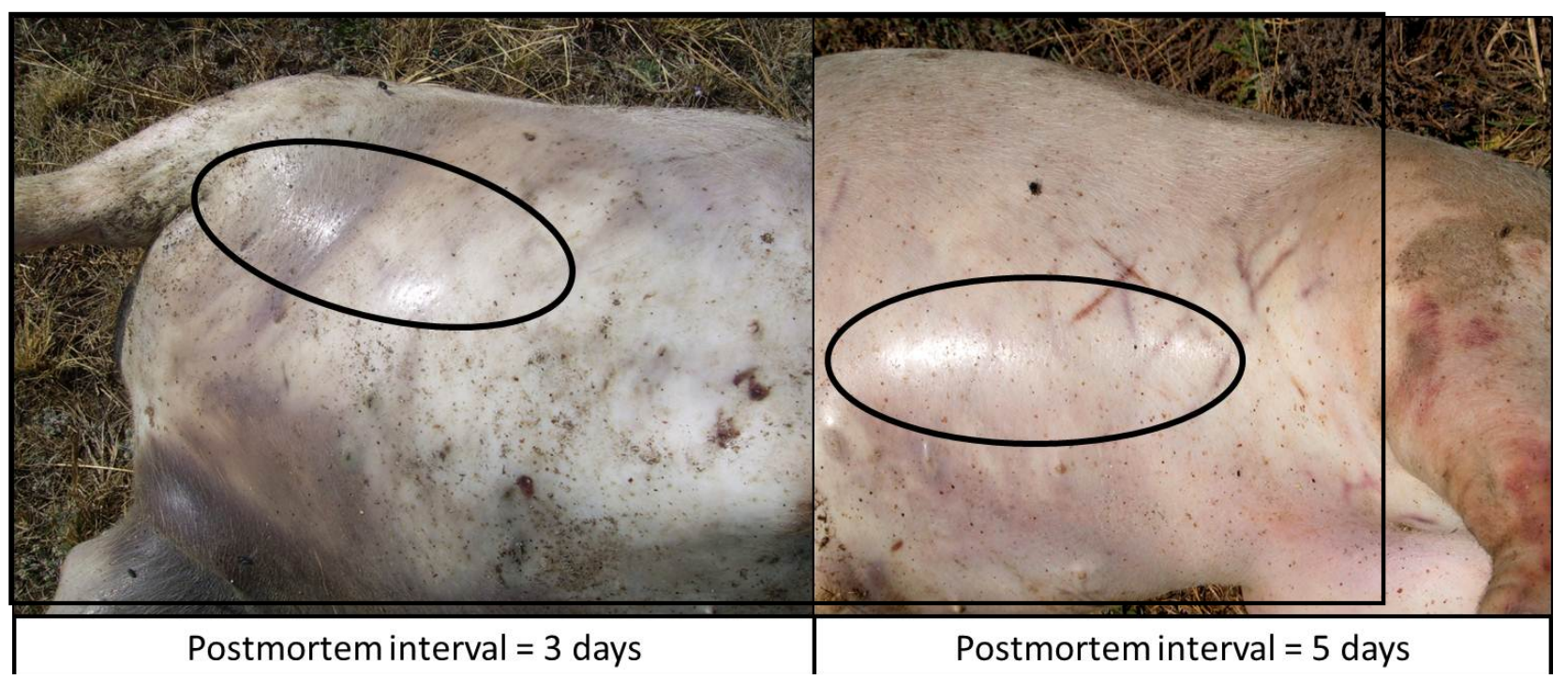

Figure 2. Glossy appearance of skin (indicated by superimposed oval shape) of the trunk/abdomen in early stages of decomposition 


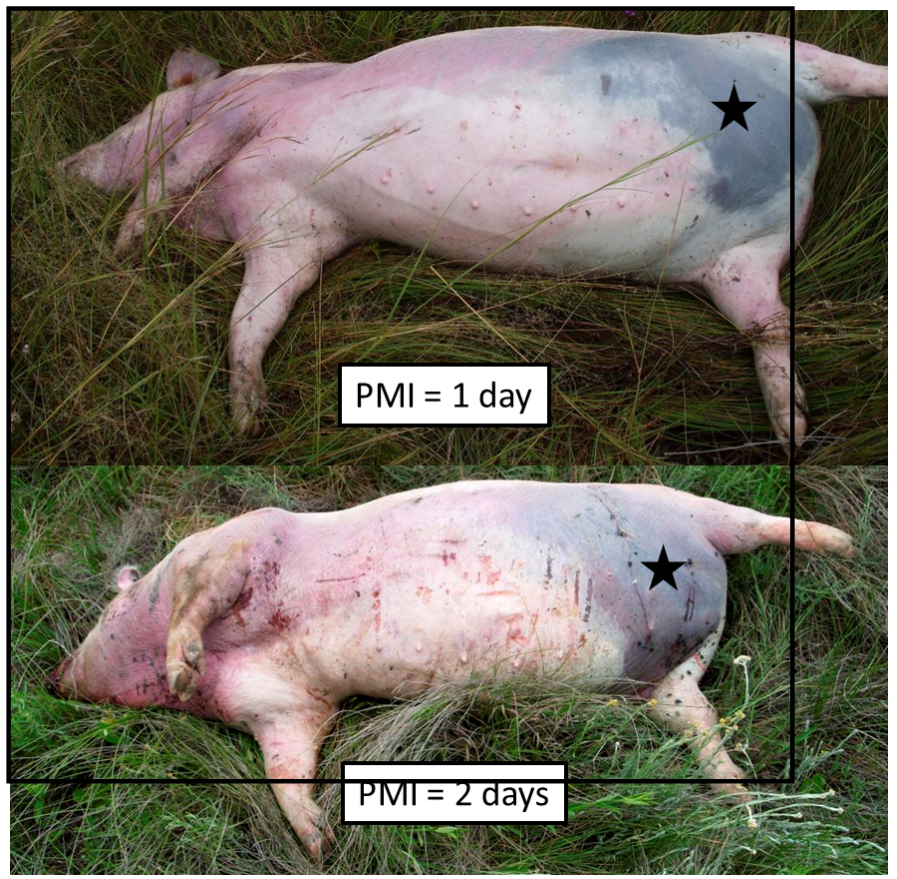

Figure 3. Purple/black discolouration (black star) noted over the lower abdominal region in early decomposition with the presence of lividity over the head and neck and trunk regions

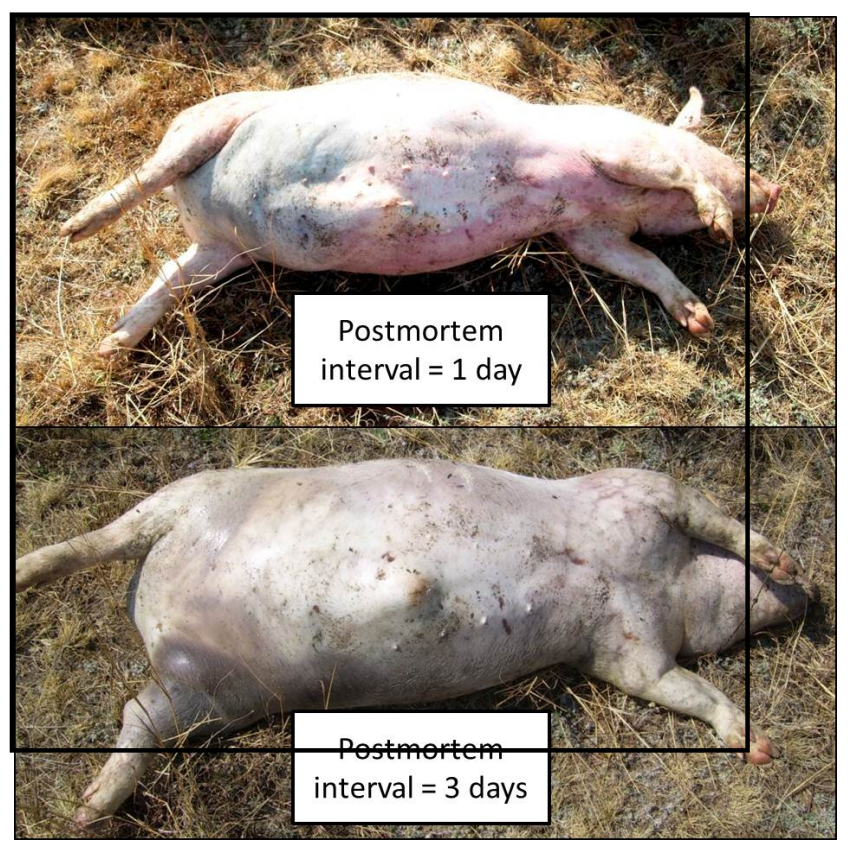

Figure 4. Early onset of bloating observed in pig carcasses with the presence of marbling $(\mathrm{PMI}=3$ days $)$ over the upper trunk region and slight blackish discolouration over abdominal region 


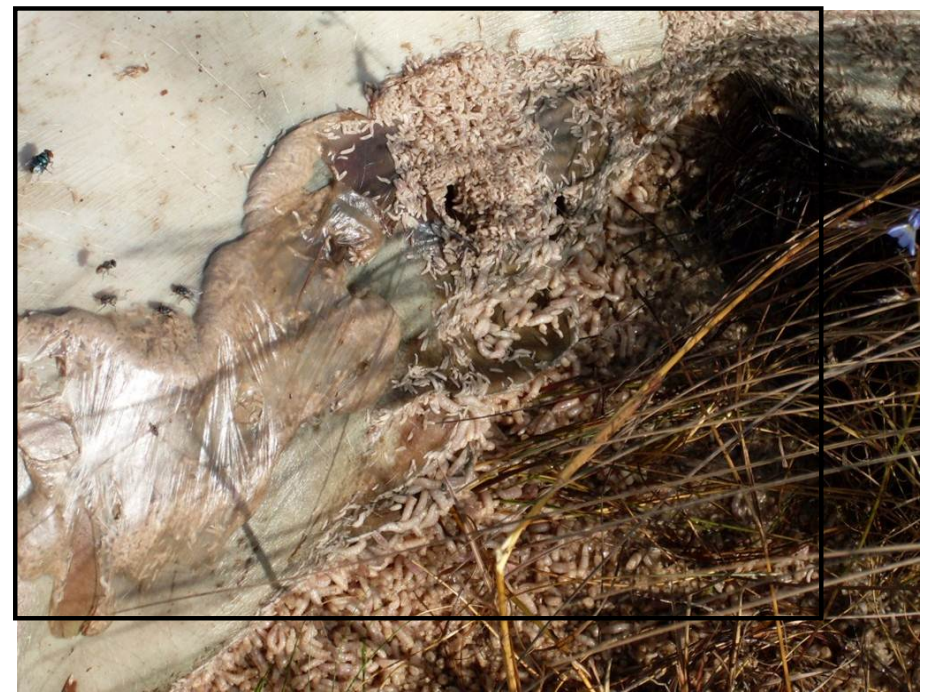

Figure 5. Postmortem bullae present over abdominal area (closest to ground) filled with maggot colonisations (maggot-filled blister)

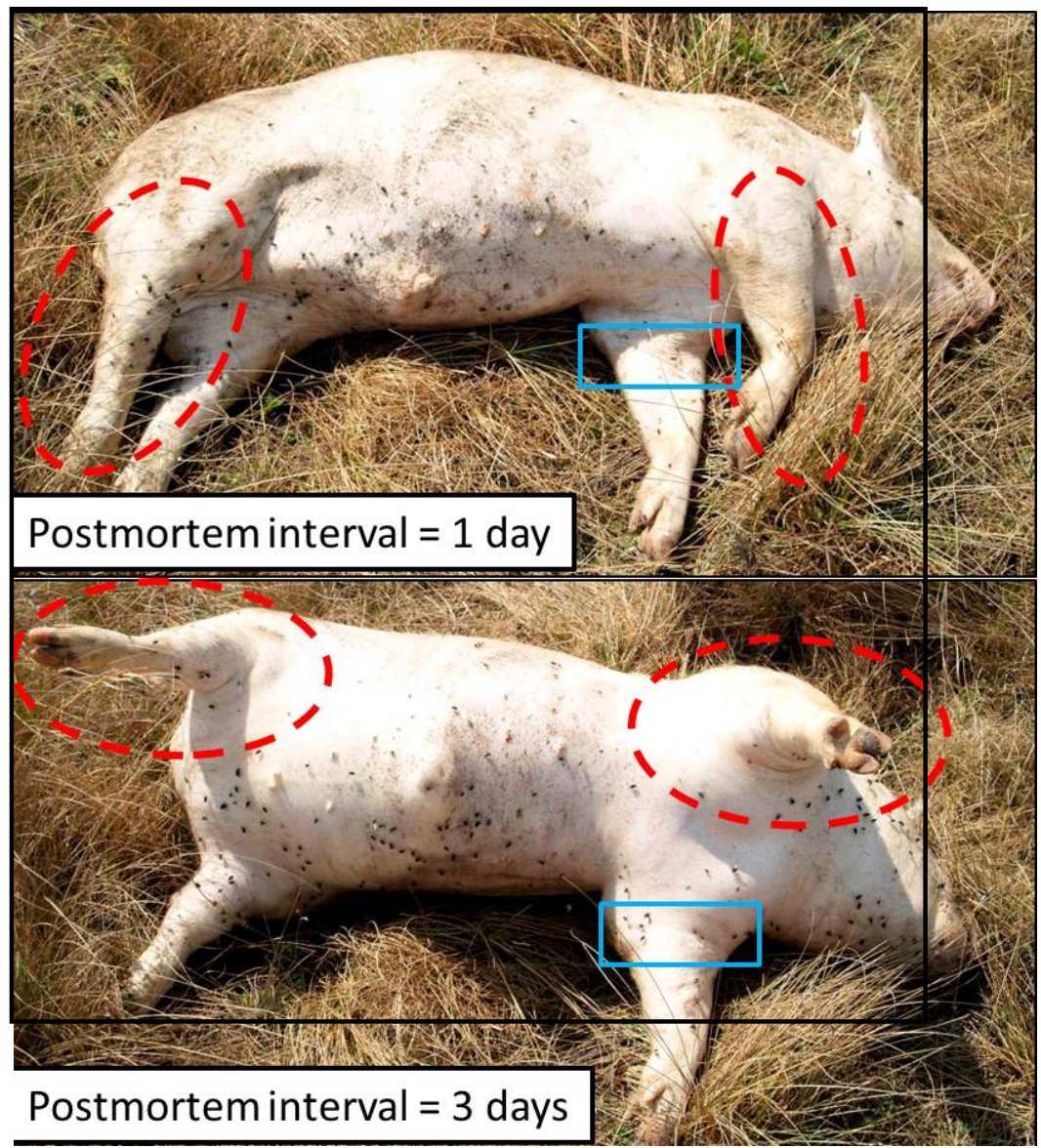

Figure 6. Rigor mortis (dotted oval) and early bloating (solid square) observed in the limbs (front and hind) 


\begin{tabular}{|c|c|c|c|c|c|c|c|c|c|c|}
\hline & FRESH & \multicolumn{9}{|c|}{ EARLY DECOMPOSITION } \\
\hline Megyesi et al 2005 & & $* *$ & \# & & & & & + & $\Delta$ & \\
\hline $\begin{array}{l}\text { Scoring for head and } \\
\text { neck }\end{array}$ & $1 \mathrm{pt}$ & \multicolumn{2}{|c|}{2 pts } & & & \multicolumn{2}{|c|}{$4 \mathrm{pts}$} & \multicolumn{2}{|c|}{$5 \mathrm{pts}$} & 6 pts \\
\hline Current study & & & & $* *$ & $\Delta$ & \# & + & & & \\
\hline
\end{tabular}

\begin{tabular}{|c|l|}
\hline KEY & \multicolumn{1}{|c|}{ OBSERVATION } \\
\hline$* *$ & Onset of skin slippage \\
\hline$\#$ & Onset of hair loss \\
\hline+ & Purging of decompositional fluids \\
\hline$\Delta$ & Onset of bloating \\
\hline
\end{tabular}

Figure 7. Discrepancies in the onset timing and therefore point allocation for skin slippage $(* *)$, hair loss $(\#)$ and bloating $(\Delta)$ as well as the purging of decompositional fluids $(+)$ in the head and neck region.

\begin{tabular}{|l|c|c|c|c|c|c|}
\hline & FRESH & \multicolumn{5}{|c|}{ EARLY DECOMPOSITION } \\
\hline Megyesi et al 2005 & & $* *$ & $\ddagger$ & & $\Delta$ & \\
\hline Scoring for trunk & $1 \mathrm{pt}$ & $2 \mathrm{pts}$ & $3 \mathrm{pts}$ & $4 \mathrm{pts}$ & $5 \mathrm{pts}$ \\
\hline Current study & & $\Delta$ & $\ddagger$ & $* *$ & \\
\hline
\end{tabular}

\begin{tabular}{|c|l|}
\hline KEY & \multicolumn{1}{|c|}{ OBSERVATION } \\
\hline$* *$ & Onset of skin slippage/hair loss \\
\hline$亡$ & Onset of marbling \\
\hline$\Delta$ & Onset of bloating \\
\hline
\end{tabular}

Figure 8. Discrepancies in the onset timing and therefore point allocation for skin slippage/hair loss $(* *)$, marbling $(\$)$ and bloating $(\Delta)$ in the trunk region. 


\begin{tabular}{|c|c|c|c|c|c|c|}
\hline & FRESH & \multicolumn{4}{|c|}{ EARLY DECOMPOSITION } \\
\hline Megyesi et al 2005 & & $* *$ & \multicolumn{2}{|c|}{} & \\
\hline Scoring for limbs & $1 \mathrm{pt}$ & $2 \mathrm{pts}$ & \multicolumn{2}{|c|}{$3 \mathrm{pts}$} & $4 \mathrm{pts}$ & $5 \mathrm{pts}$ \\
\hline Current study & & $\Delta$ & $* *$ & $\diamond$ & & \\
\hline
\end{tabular}

\begin{tabular}{|c|l|}
\hline KEY & \multicolumn{1}{|c|}{ OBSERVATION } \\
\hline$* *$ & Onset of skin slippage \\
\hline$\Delta$ & Onset of bloating (no score for Megyesi) \\
\hline$\diamond$ & Onset of hair loss (no score for Megyesi) \\
\hline
\end{tabular}

Figure 9. Discrepancies in the onset timing and therefore point allocation for skin slippage $(* *)$. Onset of bloating $(\Delta)$ as well as hair loss (\#) in the limb region is indicated as a new feature to be scored (these two features are not indicated in Megyesi's method for limbs)

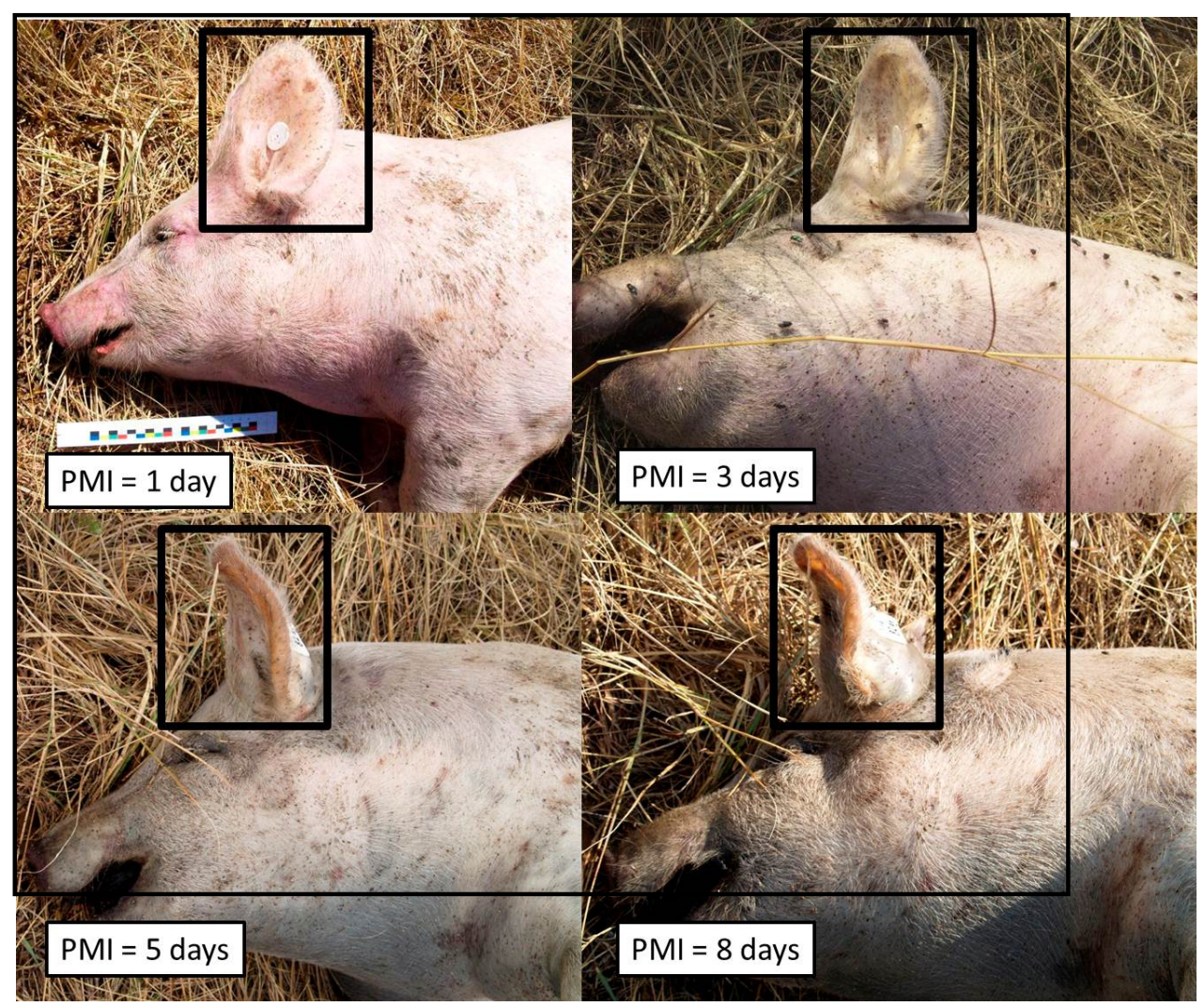

Figure 10. Progression and development of oedema of the ears observed on the pig carcasses in the earlier stages of decomposition 